\title{
Nature of Multidimensional Poverty Incidence in Rural Nepal: Empirical Evidences from Bhalam VDC, Kaski
}

\author{
Lekha Nath Bhattarai, Ph. D.*
}

\begin{abstract}
This paper attempts to exercise the Oxford Poverty and Human Development Initiative's methodology to measure the multidimensional poverty at the local (village) level. Various measures of Multidimensional poverty has been estimated and decomposed to the various sub groups of the sampled household of the then Bhalam VDC of the Kaski District, in West Nepal. Stratified random technique was applied to select the 150 sample households to conduct household survey to get required data for the measurement and analysis of poverty. The results of the analysis follows almost similar pattern of various measures of multidimensional poverty estimates of the Oxford latest study. It is also revealed from the study that multidimensional poverty incidence and intensity were highly associated with the household socioeconomic charecteristics such as Caste and ethnicity, land holding, gender and educational level of the household head and the family size.
\end{abstract}

Key words: multidimensional poverty measures, index, poverty profile, socioeconomic feature of poverty, Bhalam VDC, Nepal.

\section{BACKGROUND}

The concept of multidimensional poverty has risen to prominence among researchers and policymakers. The compelling writings of Amartya Sen, participatory poverty exercises in many countries, and the Millennium Development Goals (MDGs) all draw attention to the multiple deprivations suffered by many of the poor and the interconnections among these deprivations (Alkire and Foster, 2007). Human progress - whether it is understood as well-being, fulfillment, the expansion of freedoms, or the achievement of the MDGs - encompasses multiple aspects of life, such as being educated, employed, and well nourished. Income and consumption indicators reflect material resources that are vital for people's exercise of many capabilities. The use of monetary indicators alone, however, often reflects an assumption that these indicators are good proxies for multidimensional poverty that people who are consumption poor are nearly the same as those who suffer malnutrition, are ill educated, or are disempowered. But monetary poverty often provides insufficient policy guidance regarding deprivations in other dimensions (ibid).

Although there are many measures available as indicators to measure the human progress, the question remains how to condense social and economic indicators into lean measures that can be easily interpreted and can inform policy. The problem of too complex poverty measures has

* Dr. Bhattarai is Associate Professor at Department of Economics, Prithvi Narayan Campus, TU, Pokhara. 
troubled past initiatives. A satisfactory multidimensional poverty measure should satisfy some basic criteria. For example, it must be understandable and easy to describe; conform to notions of poverty; be able to target the poor, track changes, and guide policy; be technically solid; be operationally viable; and be easily replicable. The multidimensional poverty methodology developed by Oxford Poverty and Human Development Initiative (OPHI) meets these criteria. It is related to the user-friendly "counting" approaches but provides a more flexible way to identify who is poor (Ibid).

\section{LITERATURE REVIEW}

\subsection{An Overview of Poverty Measurement Perspectives}

Income perspective: A person is poor, if and only if, her income level is below the defined poverty line. Many countries have adopted income poverty lines to monitor progress in reducing poverty incidence. Often the cut-off poverty line is defined in terms of having enough income or a specified amount of food.

Basic needs perspective: Poverty is deprivation of material requirements for minimally acceptable fulfillment of human needs, including food. This concept of deprivation goes well beyond the lack of private income: it include the need for basic health and education and essential services that have to be provided by the community to prevent people from falling into poverty. It also recognizes the need for employment and participation.

Capability perspective: According to this perspective, poverty represents the absence of some basic capabilities to function -a person lacking the opportunity to achieve some minimally acceptable levels of the functioning. The functioning relevant to this analysis can vary from such physical ones as being well nourished, being adequately clothed and sheltered and avoiding preventable morbidity, to more complex social achievements such as partaking in the life of the community. The capability approach reconciles the notion of absolute and relative poverty, since relative deprivation in incomes and commodities can lead to an absolute deprivation in minimum capabilities.

\subsection{Measurement of Multidimensional Poverty}

The MPI is an index designed to measure acute poverty. Acute poverty refers to two main characteristics. First, it includes people living under conditions where they do not reach the minimum internationally agreed standards in indicators of basic functioning, such as being well nourished, being educated or drinking clean water. Second, it refers to people living under conditions where they do not reach the minimum standards in several aspects at the same time. In other words, the MPI measures those experiencing multiple deprivations, people who, for example, are both undernourished and do not have clean drinking water, adequate sanitation or clean fuel.

The MPI combines two key pieces of information to measure acute poverty: the incidence of poverty, or the proportion of people (within a given population) who experience multiple 
deprivations, and the intensity of their deprivation - the average proportion of (weighted) deprivations they experience. Both the incidence and the intensity of these deprivations are highly relevant pieces of information for poverty measurement. To start with, the proportion of poor people is a necessary measure. It is intuitive and understandable by anyone. People always want to know how many poor people are in a society as a proportion of the whole population.

\section{Steps to a Multidimensional Poverty Measure}

The OPHI methodology can be introduced in 12 steps. The first 6 steps are common to many multidimensional poverty measures; the remainders are more specific to OPHI methodology.

Step 1: Choose Unit of Analysis. The unit of analysis is most commonly an individual or household but could also be a community, school, clinic, firm, district, or other unit.

Step 2: Choose Dimensions. The choice of dimensions is important but less haphazard than people assume.

Step 3: Choose Indicators. Indicators are chosen for each dimension on the principles of accuracy (using as many indicators as necessary so that analysis can properly guide policy) and parsimony (using as few indicators as possible to ensure ease of analysis for policy purposes and transparency). Statistical properties are often relevant-for example, when possible and reasonable, it is best to choose indicators that are not highly correlated.

Step 4: Set Poverty Lines. A poverty cutoff is set for each dimension. This step establishes the first cutoff in the methodology. Every person can then be identified as deprived or nondeprived with respect to each dimension. For example, if the dimension is schooling ("How many years of schooling have you completed?"), "6 years or more" might identify non deprivation, while " $1-5$ years" might identify deprivation in the dimension. Poverty thresholds can be tested for robustness, or multiple sets of thresholds can be used to clarify explicitly different categories of the poor (such as poor and extremely poor).

Step 5: Apply Poverty Lines. This step replaces the person's achievement with his or her status with respect to each cutoff. For example, in the dimension of health, when the indicators are "access to health clinic" and "self-reported morbidity body mass index," people are identified as being deprived or non deprived for each indicator. The process is repeated for all indicators for all other dimensions.

Step 6: Count the Number of Deprivations for Each Person. Equal weights among indicators are assumed for simplicity. General weights can be applied, however, in which case the weighted sum is calculated.

Step 7: Set the Second Cutoff. Assuming equal weights for simplicity set a second identification cutoff, $k$, which gives the number of dimensions in which a person must be deprived in order to be considered multidimensionally poor. In practice, it may be useful to calculate the measure for several values of $k$. Robustness checks can be performed across all values of $k$. In the example $k$ is set to 4 and the persons whose data are shaded are identified as poor.

Step 8: Apply Cutoff k to Obtain the Set of Poor Persons and Censor All Nonpoor Data. The focus is now on the profile of the poor and the dimensions in which they are deprived. All information on the nonpoor is replaced with zeros.

Step 9: Calculate the Headcount $(\mathrm{H})$. Divide the number of poor people by the total number of people. For example, when $k=4$, the headcount is merely the proportion of people who 
are poor in at least 4 of $d$ dimensions. For example, two of the four people were identified as poor, so $H=2 / 4=50$ percent. The multidimensional headcount is a useful measure, but it does not increase if poor people become more deprived, nor can it be broken down by dimension to analyze how poverty differs among groups. For that reason we need a different set of measures.

Step 10: Calculate the Average Poverty Gap (A). A is the average number of deprivations a poor person suffers. It is calculated by adding up the proportion of total deprivations each person suffers and dividing by the total number of poor persons.

Step 11: Calculate the Adjusted Headcount, $\mathrm{M}_{0}$. If the data are binary or ordinal, multidimensional poverty is measured by the adjusted headcount, $M_{0}$, which is calculated as $H$ times $A$. Headcount poverty is multiplied by the "average" number of dimensions in which all poor people are deprived to reflect the breadth of deprivations.

Step 12: Decompose by Group and Break Down by Dimension. The adjusted headcount Mo can be decomposed by population subgroup (such as region, rural/ urban, or ethnicity). After constructing $M_{0}$ for each subgroup of the sample, we can break Mo apart to study the contribution of each dimension to overall poverty. To break the group down by dimension, let $A_{j}$ be the contribution of dimension $j$ to the average poverty gap $A$. $A_{j}$ could be interpreted as the average deprivation share across the poor in dimension $j$. The dimension-adjusted contribution of dgimension $j$ to overall poverty, which we call $M_{0 j}$, is then obtained by multiplying $H$ by $A_{j}$ for each dimension.

The multidimensional poverty index is composed of three dimensions made up of ten indicators. A person is considered poor if he/she deprived of at least 33.33percent of the weighted indicators. The intensity of poverty denotes the proportion of indicators in which they are deprived. The OPHI methodology has been followed to measure the different aspects of multidimensional poverty indices.

\subsection{Review of Previous Studies}

An empirical study of the multidimensional poverty was carried out by the Oxford Poverty and Human Development Initiative $(2011,2013)$ in Nepal in 2006 and 2011 at national level and disseminated the results. In these studies the head count poverty was reported alarmingly high $(64.5 \%)$ in 2006 which was letter decreased to 44.2 percent for the country as a whole. The average intensity among the poor was estimated as 52 percent and 49 percent respectively in these two reference year. The study showed that overall multidimensional poverty incidence estimated to 0.217 for the country in 2011 as compared to 0.350 in 2006 study. The percentage of population vulnerable to poverty was estimated as 15.7 percent in 2006 but it has increased to 17.4 percent in 2011. Similarly the percentage of population in severe poverty was estimated at 37.1 in 2006 which was significantly decreased to 20.8 percent in 2011 study. The 2011 study also attempted to decompose the multidimensional measures at five development regions as well revealing the fact that the lowest multidimentional poverty index was estimated for western region (0.156) followed by eastern region (0.177) whereas highest of the index was estimated for Mid-western region ( 0 . 299) followed by Far-western(0.281) and Central (0.233) regions. It is clear from the fact that Nepal achieved remarkable progress in reducing overall multidimensional poverty incidence between 2006 and 2011. However, the percentage of population vulnerable to poverty has shown 
slight increment during the same period. It reveals the fact that some proportion of the population has released from poverty incidence but some of them were still vulnerable to poverty and so it needs constant vigilance.

These two studies were conducted at national level and useful for comparing and contrasting the results of poverty measures of previous studies based on income-expenditure methods. This exercise has profound policy implication as well. However, it is now imperative to look at the poverty incidence at village level or community level exercising and applying this new methodology of poverty measurement. It would be even more significant contribution to the local development initiatives which is the priority of the county for an inclusive development of the country to get rid of the poverty incidence from the country. That is why this study would make effort in this regards.

\section{DATA AND METHODS}

This article is based solely on the primary data collected from the survey carried out during December 2012 in Bhalam VDC of Kaski district. Because of the heterogeneity of population and keeping the representation of different castes and ethnic groups in the study area only three different wards (i.e. 1, 3 and 8 wards) were selected as a sample unit for the study. Ward number 1 was mostly inhabited by Chhetries, whereas in ward number 3 Brahmins and Dalits were found dominant and in ward number 8 mostly Gurung and the people of other castes have been found living. Out of the total households of the selected wards 49 percent, 40 percent and 50 percent of households were selected respectively from wards 1,3 and 8. In this way out of total 328 households of the selected wards 150 households (45.73\%) were selected as total sample size. Stratified random techniques were applied to select the sample households. Structured interview schedule comprising the questions for required information were administered for the data collection. The collected data were coded and entered into the computer software MS Excel and relevant measures of poverty were calculated.

\section{Indicators and Measurement}

The following ten indicators were used to calculate the MPI:

- Education indicators: Education as an indicator of human development it includes two indicators each weighted equally at $1 / 6$ )

- Years of schooling: deprived if no household member has completed five years of schooling

- Child school attendance: deprived if any school-aged child is not attending school up to class 8

- Health indicators: Deprivation in health includes two indicators each weighted equally at $1 / 6$.

- Child mortality: deprived if any child has died in the family

- Nutrition: deprived if any adult or child for whom there is nutritional information is malnourished

- Standard of Living indicators: it is measured using six indicators each weighted equally at $1 / 18$. 
- Electricity: deprived if the household has no electricity

- Sanitation: deprived if the household's sanitation facility is not improved (according to MDG guidelines), or it is improved but shared with other households

- Drinking water: deprived if the household does not have access to safe drinking water (according to MDG guidelines) or safe drinking water is more than a 30 -minute walk from home roundtrip

- Floor: deprived if the household has a dirt, sand or dung floor

- Cooking fuel: deprived if the household cooks with dung, wood or charcoal

- Assets ownership: deprived if the household does not own more than one radio, TV, telephone, bike, motorbike or refrigerator and does not own a car or truck

\section{RESULTS AND DISCUSSION}

This section deals with the discussion on the results of various measures of multidimensional poverty incidence in the study area. First, overall poverty incidence has been presented and then poverty measures have been decomposed to look at poverty profile of the study site based on various socio-economic and demographic characteristics of the sample population.

\subsection{Overall State of Poverty Incidence}

The overall state of multidimensional poverty in study area was found to be slightly higher than the incidence of poverty of the country. It is also true for the intensity of the poverty. The state of overall poverty incidence is shown in the table 1.

\section{Table 1: State of Overall Poverty Incidence in the Study Area}

\begin{tabular}{lll}
\hline Particular & Units & Poverty Indicator \\
\hline Total Sample Households & Number & 150 \\
Number of Poor Households & Number/ percent & $69(46 \%)$ \\
Total Sample Population & Number & 731 \\
Total Poor population & Number/ percent & $368(50.3 \%)$ \\
Head Count Ratio (H) & Ratio & 0.503 \\
Intensity of Poverty (A) & Ratio & 0.418 \\
Multidimensional Poverty Index (MPI) & Ratio & 0.210 \\
\hline
\end{tabular}

Sources: Field Survey, 2012

Table 1 shows that $69(46 \%)$ households were found to be poor out of total sample households. However, 368 persons $(50.3 \%)$ out of the total population of the sample households were below the poverty. The intensity of the poverty (A) was estimated to be 0.418 and the multidimensional poverty index $\left(\mathrm{H}^{*} \mathrm{~A}\right)$ was estimated to be 0.210 . It means the multidimensional poverty incidence was calculated as 21 percentages in the study area.

\section{Ward Wise State of Poverty Incidence}

The study had covered sample households from the word No. 1, 3 and 8 of the studied VDC. It reveals that the incidence of poverty differs across the wards as shown in the Table 2. 
Table 2: State of Ward Wise Poverty Incidence

\begin{tabular}{lccccccc}
\hline $\begin{array}{c}\text { Word } \\
\text { No. }\end{array}$ & $\begin{array}{c}\text { Total } \\
\text { Sample } \\
\text { HHS }\end{array}$ & $\begin{array}{c}\text { Sample } \\
\text { Pop }^{\mathrm{n}}\end{array}$ & $\begin{array}{c}\text { No. of } \\
\text { Poor } \\
\text { HHs }\end{array}$ & $\begin{array}{c}\text { Poor } \\
\text { Pop }^{\mathrm{n}}\end{array}$ & $\begin{array}{c}\text { Incidence } \\
\text { of Poverty } \\
{[\mathrm{H}]}\end{array}$ & $\begin{array}{c}\text { Average } \\
\text { intensity of } \\
\text { poverty among } \\
\text { the poor [A] }\end{array}$ & $\begin{array}{c}\text { Multidimension } \\
\text { al poverty Index } \\
(\mathrm{H} \times \mathrm{A})\end{array}$ \\
\hline 1 & 75 & 349 & 30 & 168 & 0.481 & 0.432 & 0.208 \\
3 & 50 & 260 & 21 & 110 & 0.423 & 0.439 & 0.186 \\
8 & 25 & 122 & 18 & 90 & 0.738 & 0.367 & 0.271 \\
Total & 150 & 731 & 69 & 368 & 0.503 & 0.418 & 0.210 \\
\hline
\end{tabular}

Sources: Field Survey, 2012

Table 2 shows that multidimenstional poverty index was highest in ward 8 followed by ward no 1 and 3 respectively. Similar pattern was found in incidence and intensity of poverty across sample wards. It may be due to the fact that ward no 8 was inhabited heavily by the so-called lower caste dalits and ethnic groups as compared to the inhabitation of relatively higher caste people in ward no 1 and 3. It means the poverty incidence follow the socially constructed pattern of inequality persistent in Nepal. This pattern may also be due to location and geographical disparity across the wards.

\subsection{Multidimensional Poverty Profile}

A poverty profile shows the characteristic of poor and demonstrates how the measure of poverty varies across sub-group of population. Since the multidimenstional poverty measurement allows decomposing the poverty index across different sub group of sample population, it would be interesting to look at the poverty profile in the study area which is more meaningful to understand the nature and causes of poverty in the study area as well as have policy implication of the study. The following sections is devoted to the analysis across sub groups of population on the basis of level of caste and ethnicity, level of education, family size, land holding size and gender.

Household head is considered to play vital role in decision making. Nepal is generally patriarchal society. Households headed by Female are rare in Nepal. It occurs if male head has passed away or is out the village for employment. It is also believed that female could manage more economically than her male counterpart, which might have some implication for incidence of poverty. The table 3 shows that difference in poverty incidence by male and female headed households. It is exhibited that out of 69 poor households, 9 households $(36 \%)$ were found female headed as compared to 48 percentage male headed household were above the poverty line. It is clearly revealed that male headed households were found to be poor than female headed households in every respect.

The size of family is another responsible factor for determining the level of Income, living standard and poverty incidence of the household, because in large family dependent population would be higher in general. Table 3 reveals that there were about 6 percent multidimensionally poor households with the family having up to four members, whereas almost half of them were 
found poor with household having more than 8 members. It was found that as family size increases all the measures of poverty found to have increased. It is due to the fact that when family size is small family expenses would be better meet with the available income, whereas if a family has higher number of member they need higher level of income and other household amenities to subsist them which lead to higher posbility to poverty incidence and intensity. As a result, there is strong relationship between family size and poverty. It is clear that larger family size have deeply rooted in poverty circle.

Although Poverty problem spread over in all caste and ethnic groups, it is believed to be more concentrated among the dalits and ethnic group as compared to Brahmin and Chhetries. Therefore, it would be useful to look at poverty incidence and intensity across the caste and ethnic groups. Table 3 shed light in this regards. The table 3 reveals that out of total 69 absolute poor households 18 households were Brahmin, 26 households were Chetries, 11 household were Dalit and14 households were from ethnic groups. It shows that number of population below the poverty line $(\mathrm{H})$ was found to be $0.444,0.401$, 0.644, and 0.636 respectively Brahmin, Chettri, Dalit and ethnic group. The intensity of poverty of Brahmin, Chhetri, Dalit and Ethenic groups was estimated as 0.392, 0.401, 0.525 , and 0.517 respectively. Similarly the multidimensional poverty $(\mathrm{H} \times \mathrm{A})$ for Brahimin, Chettri, Dalit and ethnic group was estimated at 0.176, 0.169, 0.338, and 0.329 respectively. It is clear from the estimates that dalits group came out with highest incidence, intensity and multidimensional poverty index followed by ethnic group. In all respect of poverty indices the Brahmins and Chhetries were found relatively better off than other caste and ethnic group. This finding is consistent with the common belief regarding poverty incidence in the country.

Level of education of the household head is one of the important determining factors for the incidence of poverty or prosperity since it opens the horizons of employment and income. The purpose of comparison with the level of education has been categorized into four groups, viz. illiterate, just literate, S.L.C. and higher education. The table 3 reveals the state of poverty measures according to the level of education of the households head. It is clear from the table that incidence and intensity of poverty found to be highly associated with low level of education. Highest incidence of poverty (0.779) and intensity of poverty $(0.747)$ and multidimentional poverty index $(0.58)$ were found in the households whose head is illiterate, whereas these indices were very low $(0.098,0.25$ and 0.025 respectively) among the households having head with higher education degree. With some exception, it can be concluded that as level of education goes up the incidence found to be getting down in all respect of poverty indices. 
Table 3: Multidimensional Poverty Profile of Sample Households

\begin{tabular}{|c|c|c|c|c|c|c|c|}
\hline $\begin{array}{l}\text { Household } \\
\text { Categories }\end{array}$ & $\begin{array}{c}\text { Sample } \\
\text { HHs }\end{array}$ & $\begin{array}{l}\text { Pop }^{\mathrm{n}} \\
\text { Under } \\
\text { Sample } \\
\text { HHs }\end{array}$ & $\begin{array}{l}\text { Numbe } \\
\text { r of } \\
\text { Poor } \\
\text { HHs }\end{array}$ & $\begin{array}{c}\text { Poo } \\
\text { r } \\
\text { Pop } \\
n\end{array}$ & $\begin{array}{c}\text { Incidence } \\
\text { of } \\
\text { Poverty } \\
{[\mathrm{H}]}\end{array}$ & $\begin{array}{c}\text { Average } \\
\text { intensity } \\
\text { of } \\
\text { poverty } \\
\text { among } \\
\text { the poor } \\
\text { [A] }\end{array}$ & $\begin{array}{l}\text { Multidimens } \\
\text { ional Poverty } \\
\text { Index }(\mathrm{H} \times \mathrm{A})\end{array}$ \\
\hline \multicolumn{8}{|l|}{ Household Head: } \\
\hline Female & 25 & 120 & 9 & 44 & 0.367 & 0.215 & 0.079 \\
\hline Male & 125 & 611 & 60 & 324 & 0.53 & 0.413 & 0.219 \\
\hline \multicolumn{8}{|l|}{ Family Size: } \\
\hline Up to 4 & 81 & 245 & 23 & 69 & 0.282 & 0.225 & 0.063 \\
\hline 4 to 8 & 48 & 297 & 32 & 180 & 0.606 & 0.547 & 0.331 \\
\hline 8 and above & 21 & 189 & 14 & 119 & 0.63 & 0.69 & 0.435 \\
\hline \multicolumn{8}{|c|}{ Caste and Ethnicity: } \\
\hline Brahmin & 54 & 198 & 18 & 88 & 0.444 & 0.392 & 0.176 \\
\hline Chettri & 57 & 278 & 26 & 117 & 0.421 & 0.401 & 0.169 \\
\hline Dalit & 15 & 104 & 11 & 67 & 0.644 & 0.525 & 0.338 \\
\hline Ethnic group & 24 & 151 & 14 & 96 & 0.636 & 0.517 & 0.329 \\
\hline \multicolumn{8}{|c|}{ Level of Education } \\
\hline Illiterate & 44 & 140 & 27 & 109 & 0.779 & 0.747 & 0.582 \\
\hline J. literate & 40 & 305 & 21 & 147 & 0.482 & 0.251 & 0.121 \\
\hline S.L.C. & 50 & 143 & 18 & 98 & 0.685 & 0.345 & 0.236 \\
\hline Higher Education & 16 & 143 & 3 & 14 & 0.098 & 0.25 & 0.025 \\
\hline \multicolumn{8}{|c|}{ Status of Land Ownership: } \\
\hline Having land & 138 & 663 & 61 & 325 & 0.492 & 0.278 & 0.137 \\
\hline Not having land & 12 & 68 & 8 & 42 & 0.618 & 0.437 & 0.270 \\
\hline \multicolumn{8}{|c|}{ Size of land Holding: } \\
\hline \multicolumn{8}{|l|}{ Ropani } \\
\hline 1-4 Ropani & 78 & 358 & 33 & 179 & 0.50 & 0.35 & 0.173 \\
\hline 4-8 Ropani & 36 & 220 & 18 & 110 & 0.50 & 0.32 & 0.160 \\
\hline $\begin{array}{l}8 \text { Ropani and } \\
\text { above }\end{array}$ & 16 & 61 & 2 & 10 & 0.164 & 0.112 & 0.018 \\
\hline Total & 150 & 731 & 69 & & & & \\
\hline
\end{tabular}
Sources: Field Survey, 2012

Having landholding title or not deserve an important implication to poverty incidence in Nepal since Nepal still an agrarian economy. Overwhelming majority of households in Nepal hold some piece of land where they are settled or have raised their livelihood based on farming. It would be quite difficult to those household to be out of poverty that are land less or settled in scattered settlement. It is evident from the table that 12 sample households were landless out of them 8 were poor. The incidence of poverty among these household was estimated as 0.618 and the average incidence was estimated to be 0.437 which is quite high as compared to those who won some land 
title. The multidimensional poverty index among the landless was 0.27 as compared to just 0.137 among the household having some land title. Thus, it is clear that not having land is an important deprivation to the people living in rural area.

Similarly, the size of landholding is another important indicator of economic status of people the may cause difference in living standard option to the people in rural setting. Actually size matters in landholding. This study has categorized the households with land holding into four groups, viz. up to 1 ropani, 1 to 4 ropani, 4 to 8 ropani and 8 ropani and above. Table 3 depicts some estimates of poverty estimates by landholding groups. It reveals that with the increase in the size of landholding, the poverty indices were getting down with respect to incidence, intensity and multidimensional indices. It is clear from the fact that about half of the people were found multidimenstionally poor having landholding up to 1 ropani whereas it was just about 2 percentage who own land above 8 ropani.

\section{CONCLUSION}

This study was an exercise of recently devised methodology to access the state and intensity of poverty at the local level. The application of the methodology found to be more simple and suitable to measure the state and intensity of poverty at local level where per capita income and expenditure data are either not reliable or difficult to collect. Since it uses more state forward indicators it can be easily decomposed to the sub-groups of population as well. The findings of the present study suggest that the incidence of multidimensional poverty in the study area follows almost similar pattern as that of the national scenario. From the multidimensional poverty profile it is reflected that the incidence of poverty has direct bearing on the socioeconomic and demographic characteristics of the households, such as household size, gender of the households head and his educational level, land entitlement and size of the 1 ropani and its holding. From this exercise it is felt that it would be easier to find out incidence of poverty and to decompose the poverty measures to various socio- economic sub-group of population at local level. Practicing this methodology by the local authorities could be highly helpful for identifying the poor and to employ various targeted programs and policies for inclusive development.

\section{REFERENCES}

Alkire, S. (2002). "Dimensions of human development". World Development, vol. 30(2): 181-205. Alkire, S. and Santos, M.E. (2013), "Measuring Acute Poverty in the Developing World:

Robustness and Scope of the Multidimensional Poverty Index", OPHI Working Paper 59. Available at: www.ophi.org.uk/wp-content/uploads/ophi-wp-59.pdf.

Alkire, S. and Foster, J. (2007). "Counting and Multidimensional Poverty Measures". OPHI Working Paper Series 7, Accessed from www.ophi.org.uk.

Oxford Poverty and Human Development Initiative [OPHI] (2013). "Nepal Country Briefing", Multidimensional Poverty Index Data Bank. OPHI, University of Oxford. Available at: www.ophi.org.uk/multidimensional-poverty-index/mpi-country-briefings/.

UNDP (1997) Poverty in the human development perspective: concept and measurement, Chapter

1. Human Development Report 1997.Available at: www. undp.org/hdr/reports 